\title{
Changing Trend of Rectal Prolapse Surgery in the Era of the Minimally Invasive Surgery
}

\author{
Suk-Hwan Lee, M.D. \\ Department of Surgery, Kyung Hee University Hospital at Gangdong, Kyung Hee University School of Medicine, Seoul, Korea
}

\begin{abstract}
With the life span of the general population increased, rectal prolapse in elderly patients became a major concern in terms of the decision of the treatment modalities and quality of life of patients. Most elderly patients with rectal prolapse in the past received a perineal approach with the fear of general anesthetic complications rather than the abdominal approach. However, improvement in perioperative care in anesthesiology and minimally invasive surgery, the trend of surgical management of rectal prolapse is rapidly changing. Minimally invasive surgery including the laparoscopic and robotic surgeries showed comparable short-term outcomes even in elderly patients. Recently published guidelines also recommended a laparoscopic abdominal approach for the management of rectal prolapse.
\end{abstract}

Keywords: Rectal prolapse, Laparoscopy, Surgery
Received November 13, 2019

Accepted November 13, 2019

Corresponding author

Suk-Hwan Lee

Department of Surgery, Kyung Hee University Hospital at Gangdong,

Kyung Hee University School

of Medicine, 892 Dongnam-ro,

Gangdong-gu, Seoul 05278, Korea

Tel: +82-2-440-6134

Fax: +82-2-440-6073

E-mail: leeshdr@khu.ac.kr

ORCID:

https://orcid.org/0000-0001-6470-8620

Copyright $\odot 2019$ The Journal of Minimally Invasive Surgery. All rights reserved.
This is an Open Access article distributed under the terms of the Creative Commons Attribution Non-Commercial License (http:// creativecommons.org/licenses/by-nc/4.0/) which permits unrestricted non-commercial use, distribution, and reproduction in any medium, provided the original work is properly cited.
With the increasing average life span of the population, a larger number of elderly patients require medical attention. Rectal prolapse is a disease of older women after giving birth and can be associated with concomitant pelvic floor disorders, such as pelvic organ prolapses and fecal incontinence. Patients with rectal prolapse not only suffer from the symptoms themselves but also experience a worsening quality of life and social isolation. Nonoperative management, such as medication or biofeedback, may relieve the symptoms; however, surgery is the only way to cure the symptoms.

More than 100 operations have been introduced to manage rectal prolapse in the surgery textbook. No single approach has been proven superior to another. Traditionally, there are two surgical approaches, perineal and abdominal. Many published guidelines recommend a perineal approach for unhealthy patients with general anesthesia or abdominal procedures. ${ }^{1-3}$ On the other hand, with the improvement of perioperative care, the absolute contraindication to general anesthesia is decreased markedly.

Generally, the perineal approach shows less morbidity but a higher recurrence rate. In contrast, the abdominal approach shows increased morbidity but a lower recurrence rate. The abdominal approach meant open surgery in the past. Minimally invasive surgery has already shown improved shortterm outcomes, such as less pain, shortened length of stay, and a faster return to work. The traditional abdominal rectal prolapse approach has been changing rapidly. Laparoscopic or robotic approaches are being adopted more commonly. ${ }^{4-6} \mathrm{Re}^{-}$ cent randomized studies showed no differences in morbidity or recurrence rates between perineal and laparoscopic abdominal approaches. ${ }^{7}$ New guidelines also recommend laparoscopic or minimally abdominal approaches for rectal prolapse surgery. ${ }^{1-3}$ 
In this issue, a retrospective study of the surgical treatment of rectal prolapse also showed this changing trend of surgical management. ${ }^{8}$ Although the number of patients is not enough to make any solid conclusions, among 18 abdominal approaches, laparoscopic approaches comprised 16 operations (88.9\%). Surgical methods were variable; laparoscopic rectopexy with mesh procedures was most common, followed by laparoscopic resection rectopexy. The recurrence rate after the primary operation was $12.8 \%$, whereas that of repeated operation was $0 \%$. One of the main limitations of this study was a lack of long-term follow-up and functional outcomes after surgery.

Research concerning rectal prolapse in Asian countries is scarce. Most of them were small case series., ${ }^{5,69-11}$ Asian populations generally show a lower body mass index (BMI) than western populations. The benefit of minimally invasive surgery is more prominent in low BMI populations. More solid evidence based on well-designed clinical trials will be needed.

\section{ORCID}

Suk-Hwan Lee, https://orcid.org/0000-0001-6470-8620

\section{CONFLICT OF INTEREST}

None.

\section{FUNDING}

None.

\section{ACKNOWLEDGMENTS}

None.

\section{REFERENCES}

1) Bordeianou L, Paquette I, Johnson E, et al. Clinical Practice
Guidelines for the Treatment of Rectal Prolapse. Dis Colon Rectum 2017;60:1121-1131.

2) Gallo G, Martellucci J, Pellino G, et al. Consensus Statement of the Italian Society of Colorectal Surgery (SICCR): management and treatment of complete rectal prolapse. Tech Coloproctol 2018;22: 919-931.

3) van der Schans EM, Paulides TJC, Wijffels NA, Consten ECJ. Management of patients with rectal prolapse: the 2017 Dutch guidelines. Tech Coloproctol 2018;22:589-596.

4) Albayati S, Chen P, Morgan MJ, Toh JWT. Robotic vs. laparoscopic ventral mesh rectopexy for external rectal prolapse and rectal intussusception: a systematic review. Tech Coloproctol 2019;23:529-535.

5) Hyun K, Yang S-J, Lim K-Y, Lee J-K, Yoon S-G. Laparoscopic Posterolateral Rectopexy for the Treatment of Patients With a Full Thickness Rectal Prolapse: Experience With 63 Patients and Short-term Outcomes. Ann Coloproctol 2018;34:119-124.

6) Kiyasu Y, Tsunoda A, Takahashi T, Nomura M. Laparoscopic ventral rectopexy with sacrocolpopexy for coexisting pelvic organ prolapse and external rectal prolapse. J Anus Rectum Colon 2018; 1:141-146.

7) Senapati A, Gray RG, Middleton LJ, et al. PROSPER: a randomised comparison of surgical treatments for rectal prolapse. Colorectal Dis 2013;15:858-868.

8) Nacion AJD, Park YY, Kim HS, Yang SY, Kim NK. Surgical treatment of rectal prolapse: a 10-year experience at a single institution. J Minim Invasive Surg 2019;22:164-170.

9) Hashida H, Sato M, Kumata Y, et al. Usefulness of laparoscopic posterior rectopexy for complete rectal prolapse: A cohort study. Int J Surg 2019;72:109-114.

10) Iida $Y$, Honda K, Saitou H, Munemoto Y, Tanaka H. Modified Gant-Miwa-Thiersch procedure (mucosal plication with anal encircling) for rectal prolapse. Colorectal Dis 2019;21:588-594.

11) Tsunoda A, Takahashi T, Matsuda S, Oka N, Kusanagi H. Midterm functional outcome after laparoscopic ventral rectopexy for external rectal prolapse. Asian J Endosc Surg 2019 Mar 28 [Epub]. DOI: 10.1111/ases.12701. 